\title{
Placeres diamantíferos do Rio Itiquira, MT, Brasil
}

\author{
Diamond placers of the Itiquira River, MT, Brazil
}

\author{
ELVIO FIGUEIREDO SANTANA*, RICARDO KALIKOWSKI WESKA ** \\ *DRM - ICET - UFMT (elviocuiabano@hotmail.com) \\ **DRM - ICET - UFMT (rweska@ufmt.br)
}

\begin{abstract}
Resumo
Itiquira situa-se a SE de Cuiabá, no Estado de Mato Grosso e está inserida no contexto geológico da porção NW da Bacia do Paraná, que do mais antigo para o mais jovem são coberturas cretáceas (Formação Marília), terciárias (Formação Cachoeirinha) e quaternárias (Formação Pantanal). Os cascalhos inconsolidados desta última unidade são hospedeiros de diamantes, que são explorados às margens do Rio Itiquira nos garimpos conhecidos por Cambaúva, Cavoqueiro, Bode e fazendas Formosa e Velha. Os primeiros registros sobre a extração de diamantes dos cascalhos diamantíferos remontam ao século XX, ano de 1930 e ocorreram no garimpo do Cavoqueiro, situado na margem direita do rio a aproximadamente $1 \mathrm{~km}$ a jusante da cidade. A região experimentou alta atividade garimpeira e descoberta de novas frentes até o ano de 1940. Desde então os garimpos entraram em declínio e a descoberta de novas frentes também. Foram realizados mapeamentos geológicos das frentes abandonadas que permitiram o empilhamento estratigráfico dos placeres, aos quais adicionamos informações sobre a idade absoluta e o estudo de química mineral em concentrados. A associação das informações geológicas e de geocronologia evidencia a existência de três eventos deposicionais aqui informalmente denominados de T0 a T2, distribuídos ao longo do canal, planícies e terraços laterais mais antigos. Utilizamos a técnica de LOE (Luminescência Opticamente Estimulada) para cinco amostras coletadas desde o canal até o terraço mais elevado. A idade mais jovem, de $660 \pm 90$ anos, foi obtida na amostra EIT 13 e a idade mais antiga, de $8400 \pm 858$ anos, na amostra EIT 05, ambas em terraço T1. O conjunto de idades mostra que os terraços diamantíferos foram depositados a partir do Holoceno e retrabalhados até $660 \pm 90$ anos. Amostras coletadas para estudo dos minerais pesados foram analisadas em lupa e microssonda eletrônica. Os minerais identificados foram as granadas G0, G3, G4 e G4D; o rutilo; a ilmenita; a safira; o zircão; e, óxidos secundários de ferro. A maioria dos minerais identificados não mostra associação com fontes primárias férteis em diamante, com exceção da granada G4D.
\end{abstract}

Palavras-chave: Itiquira, diamante, placeres, armadilhas, idade, minerais indicadores

\begin{abstract}
Itiquira is situated SE of Cuiabá, in the Mato Grosso State, and is inserted in the geological context of NW portion of the Paraná Basin, which from oldest to youngest includes the Cretaceous Marilia Formation, the Tertiary Cachoeirinha Formation and the Quaternary Pantanal Formation. Unconsolidated gravels from the latter unit host diamonds that are mined on the rivers known for rudimentary mining in Itiquira: Cambaúva, Cavoqueiro, Bode and Formosa and Velha farms. First records on the extraction of diamonds from these gravels date to the twentieth century, 1930, and took place in the artisanal mining Cavoqueiro, located on the right bank of the river, about $1 \mathrm{~km}$ downstream of the city. The region experienced high mining activity and the discovery of new mining areas by the year of 1940 . Since then, the artisanal mining and the discovery of new fronts went into decline. We carried out geological mapping of abandoned fronts allowing the stratigraphic stacking of the placers, determination of their absolute age and study of the chemistry of mineral concentrates. The combination of geological and geochronological studies demonstrate the existence of three depositional events here informally termed T0 to T2, distributed along the channel, plains and older terraces on both sides. We used the LOE (Optically Stimulated Luminescence) dating technique for five samples collected from the channel to the highest terrace. The youngest age of $660 \pm 90$ years, was obtained in the sample EIT 13 and the oldest with $8400 \pm 858$ years in the sample EIT 05, both samples at T1 terrace. The ages show that part of these diamondiferous flats were deposited from the Holocene, and reworked until $660 \pm 90$ years. Heavy mineral samples collected for the study were examined with magnifying glass and analyzed by electron microprobe. The minerals identified were the garnets G0, G3, G4 and G4D, rutile, ilmenite, sapphire, zircon, and secondary iron oxides. Most of the identified mineral shows no close association with fertile diamond primary sources, with the exception of the garnet G4D.
\end{abstract}

Keywords: Itiquira, diamond, placers, traps, age, mineral indicator 


\section{Introdução}

O estudo de depósitos de placeres no Brasil foi intensificado nas últimas décadas por apresentar grande importância econômica, como hospedeiros de recursos minerais com destaque para o diamante. Em Mato Grosso, potencialmente existem placeres diamantíferos extensos e espessos, decorrentes do condicionamento climático favorável ao intemperismo e como parte da evolução da Bacia do Pantanal. Rios como o Paraguai, Cuiabá, das Mortes, Itiquira, entre outros, ao longo de ambas as margens comportam placeres diamantíferos. Nestas últimas décadas, este potencial posiciona Mato Grosso entre os principais estados produtores de diamante. Por décadas a história de Itiquira esteve intimamente relacionada à descoberta e garimpagem de depósitos diamantíferos ao longo do rio Itiquira e em várias frentes (Marques 2004). Dos inúmeros vestígios de garimpos existentes, cinco foram estudados: Cambaúva, Cavoqueiro, Bode e fazendas Formosa e Velha. Neste estudo foi possível realizar mapeamento dos pacotes mineralizados em diamante, obtendo-se as características litológicas e empilhamento estratigráfico. Ademais, foram obtidas cinco idades absolutas pelo método de quartzo luminescência em pacotes areno-cascalhosos posicionados em distintas cotas

topográficas no vale, assim como estudo preliminar sobre a existência de minerais pesados indicadores de fontes primárias diamantíferas kimberlítica ou outras.
As frentes de garimpos de diamante pesquisadas situam-se na porção extremo SE do Estado de Mato Grosso, no Município de Itiquira, distribuídas em uma área de cerca de $100 \mathrm{~km} 2$, na fronteira entre os estados de Mato Grosso e Mato Grosso do Sul (Figura 1).

De Cuiabá a Itiquira o acesso é feito pela BR 163. Esta BR interliga Cuiabá a Campo Grande e passa por Rondonópolis. A partir desta cidade até o trevo de acesso a Itiquira, no entroncamento com a MT 370 são71 km. Deste trevo até Itiquira, à distância é de $76 \mathrm{~km}$ e o percurso total a partir de Cuiabá soma $362 \mathrm{~km}$. Os acessos às diferentes frentes de garimpos foram realizados através de estradas vicinais (Figura 1). Estas estradas, em grande parte, foram construídas pelos garimpeiros e hoje constituem as principais vias que interligam a cidade com fazendas e chácaras em Itiquira.

\section{Materiais e métodos}

O mapeamento geológico de pontos e das frentes de garimpos de diamantes (Figura 2) foi na escala entre 1:100 a 1:1.000. Foram descritas as características litológicas, bem como a sequência cronológica preliminar dos eventos deposicionais desde o canal atual até os terraços laterais mais elevados e, em princípio, os mais antigos. A compilação dos variados pontos permitiu a elaboração de dois perfis aproximadamente perpendiculares ao canal do Rio Itiquira (Figura 2), que foram plotados sobre a base cartográfica Folha Itiquira, SE. 21-X-D-III, DSG, 1976.

\section{Localização e vias de acesso}

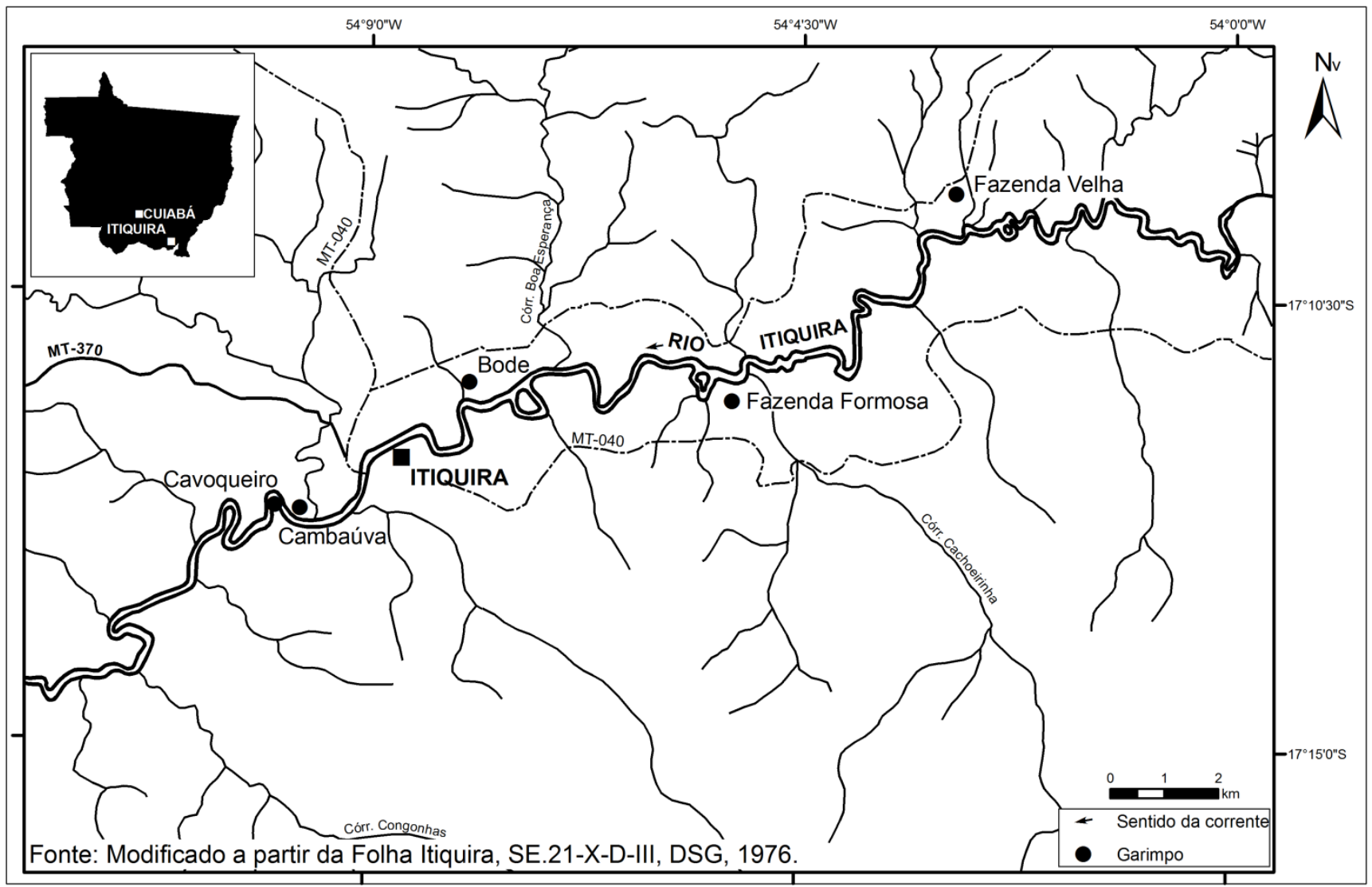

Figura 1 - Mapa de localização e acessos ao município de Itiquira e garimpos estudados. 
Estudos de fácies e de armadilhas (traps), de acordo com Weska et al. (1984) e Weska (1996a), suportaram a coleta de amostras de minerais pesados, Figura 3A.

O método utilizado para a datação foi LOELuminescência Opticamente Estimulada, que se baseia na interação da radiação ionizante (radiação $\gamma$, partícula $\beta$ e partícula $\alpha$ ) com o cristal natural. Quando a radiação incide sobre o cristal, ocorre a ionização do mesmo, com a criação de pares de cargas positivas e negativas no seu interior (Tatumi et al. 2008). As idades foram obtidas no Laboratório de Vidros e Datação da FATEC, Faculdade de Tecnologia de São Paulo. As amostras foram coletadas em poços de 0,90 $\mathrm{m}$ de diâmetro e de profundidade, com ambiente livre de ações antrópicas, de animais (zoorturbações) ou de plantas (fitoturbações) (Sallun et al. 2007). Os amostradores foram tubos de PVC, com $0,40 \mathrm{~cm}$ de diâmetro e tampões com anel de borracha para vedar as extremidades (Figura 3B). Em laboratório estas amostras, nas frações 0,88 a $0,18 \mathrm{~mm}$, foram submetidas à lavagem com $\mathrm{H} 2 \mathrm{O} 2, \mathrm{HCl}$ e $\mathrm{HF}$, intercalados por enxágues de água destilada, para eliminar vestígios de matéria orgânica, carbonato e ionização do quartzo proveniente das partícula $\alpha$ que atuam na superfície do grão. Um ímã foi utilizado para separar minerais magnéticos da amostra, que em seguida foram imersos em politungstato de sódio para separar a fração de minerais pesados. Etapas subsequentes permitiram a determinação das doses acumuladas natural e anual. A dose acumulada natural foi obtida através do equipamento OSL Automated Systems, modelo 1100-series, Daybreak Nuclear Instruments Inc. Esta dose resulta de medidas das intensidades de LOEnat e as LOEres + irradiação, com incidência de luz azul e detecção no UV pelo método de regeneração total. A partir daí, é feita a curva de calibração onde são inseridos os valores de LOEnat. O ajuste dos pontos experimentais de intensidade de LOE no valor de pico, quando comparados com valores de doses conhecidas nos fornecem o valor da dose acumulada em Gy. A dose acumulada anual foi medida por estação espectroscópica portátil Canberra Inspector com detector: Nal - Tl. As amostras em recipiente plástico são colocadas em um espectrômetro para medidas durante 24 h. Este equipamento faz uma varredura de energia e fornece uma relação de Contagem versus Energia. A partir desta relação, são extraídos os valores de intensidade de contagem referentes à energia dos elementos U (Urânio), Th (Tório), K (Potássio). A idade em anos resulta da equação: Dose Acumulada Natural (Gy)/Dose Anual (Gy/ano).

A prospecção de minerais pesados indicadores foi realizada nos cascalhos diamantíferos que ocorrem no rio e alguns afluentes, desde o canal até os terraços. $O$ volume por amostra foi de 50 litros. As amostras em campo foram separadas granulometricamente em peneiras (Figura 3C e D) utilizadas em garimpos de diamantes, denominadas popularmente de refina $1,6 \mathrm{~mm}$; fina $2 \mathrm{~mm}$; média $3,6 \mathrm{~mm}$; grossa $6 \mathrm{~mm}$ e sururuca $20 \mathrm{~mm}$. O resíduo final abaixo de 1,6 $\mathrm{mm}$ foi concentrado em bateia. Em laboratório os concentrados foram novamente separados nas frações abaixo de $0,125 \mathrm{~mm}$, entre 0,125 a 0,5 mm e acima de 0,5 $\mathrm{mm}$. A fração entre 0,125 a $0,5 \mathrm{~mm}$ permitiu a qualificação dos minerais por identificação em lupa binocular. Entre 0,5 $\mathrm{mm}$ a $1 \mathrm{~mm}$, os grãos destes pesados foram destinados à confecção de seções para o estudo da química mineral. Estas seções foram confeccionadas no Laboratório de Laminação da Universidade de Brasília (UNB) e analisadas no Laboratório de Microssonda Eletrônica da Universidade Federal do Rio Grande do Sul (UFRGS). O equipamento utilizado foi o Cameca Camebax BX50.

\section{Contexto geológico regional}

O Rio Itiquira drena a porção NW da Bacia do Paraná e deságua na Bacia do Pantanal. Os tipos litológicos que compõem o bedrock dos placeres diamantíferos deste rio, do mais antigo para o mais jovem, de acordo com Vasconcelos (2007), são: os grupos Guatá (Formação Palermo), Passa Dois (Formação Irati) e Bauru (Formação Marília). A Formação Cachoeirinha cobre as unidades anteriores e é coberta por Aluviões Atuais.

Em Mato Grosso as Aluviões Atuais constituem a Formação Pantanal, conforme Oliveira \& Leonardos (1943), com depósitos aluvionares constituídos por vasas, areias e argilas de deposição recente que ocorrem no Pantanal mato-grossense. Almeida (1959) discorreu sobre esta unidade como depositada em uma das maiores planícies no interior do continente, com entulhamento influenciado pela orogenia Andina e o ambiente deposicional fluvial e/ou flúvio-lacustre.

Falhas distensivas NE, (Figura 4) delimitam aproximadamente a calha do Rio Itiquira. Regionalmente estas falhas são paralelas a Falha de Poxoréo, que marca a borda entre o graben e o horst do Rifte Rio das Mortes (Weska et al. 1996, Weska 1996, Gibson et al. 1997) e que foram reativadas pelo impacto da Pluma de Trindade durante o Cretáceo.

\section{Os placeres}

Os placeres estudados estão distribuídos em depósitos desde o canal até os terraços laterais (Figuras 5A a D). São compostos por cascalhos na base e areia a argila no topo. Os cascalhos ao longo do rio cobrem, por discordância erosiva, rochas mais antigas do Terciário ao Permiano. $\mathrm{Na}$ área estudada normalmente o bedrock dos cascalhos diamantíferos é de tipos litológicos da Formação Marília, 


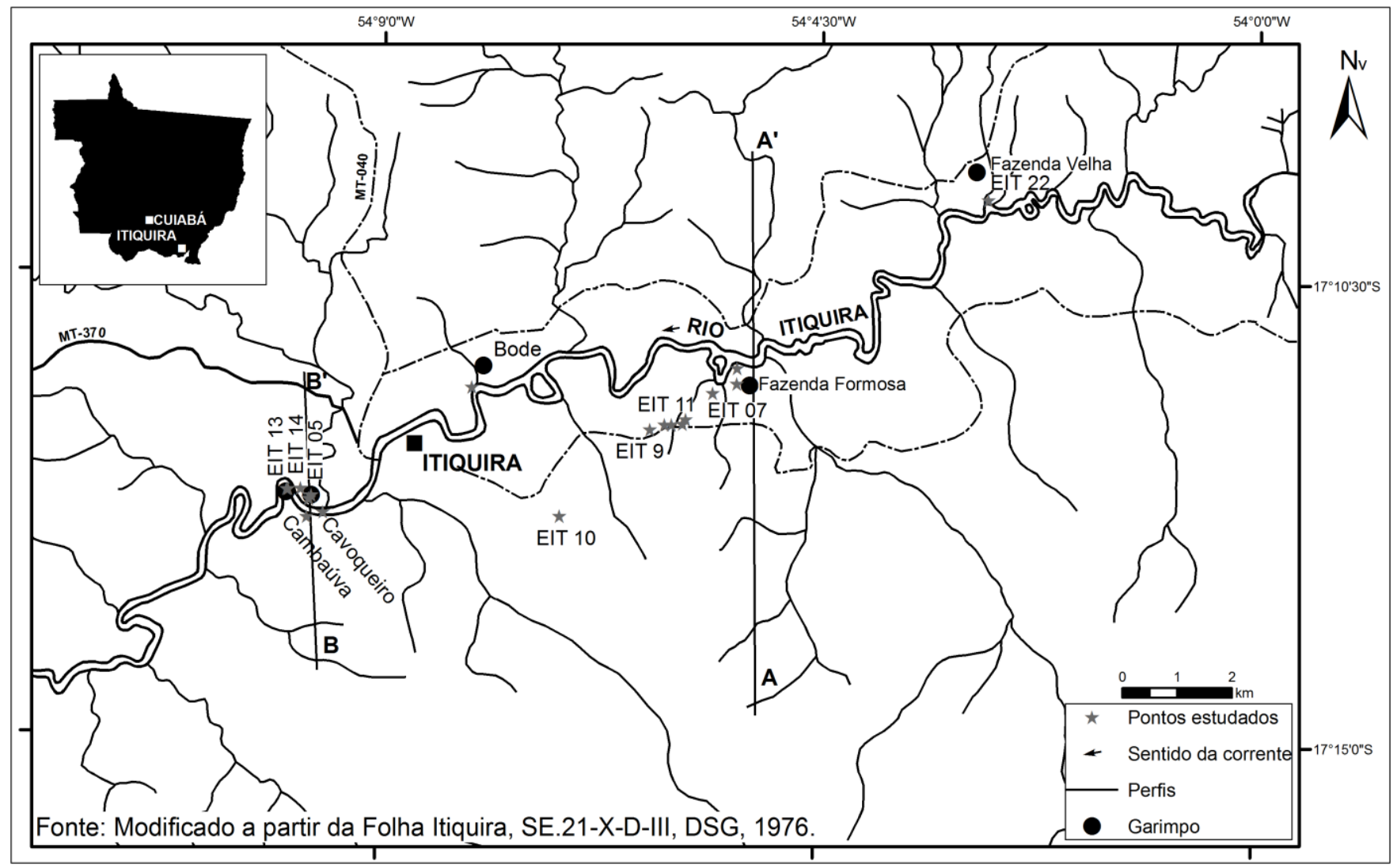

Figura 2 - Mapa de localização dos pontos estudados e os perfis $\mathrm{AA}^{\prime}$ e $\mathrm{BB}^{\prime}$.

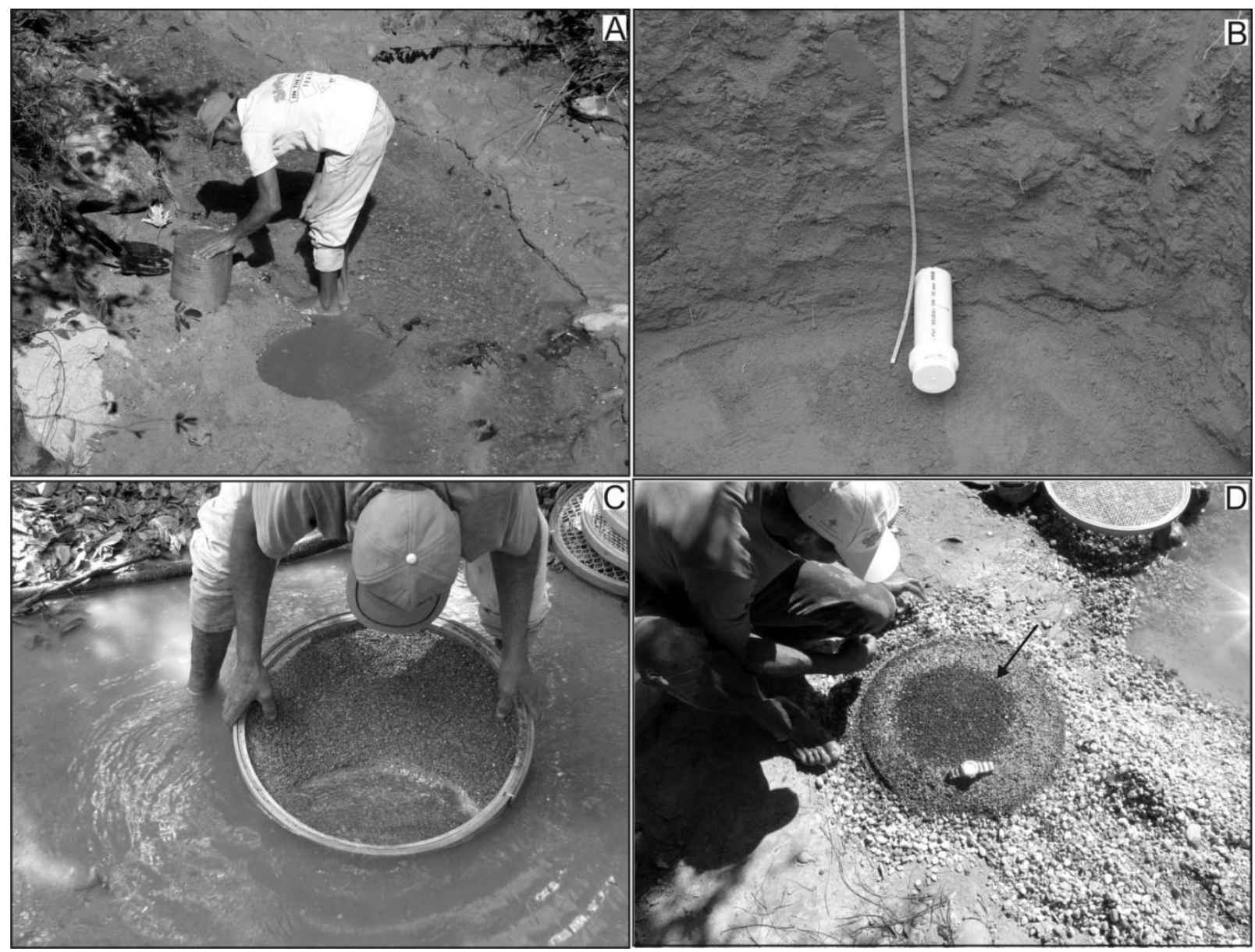

Figura 3 - Amostragem e concentração. Em A, para minerais pesados. Em B, para datação. Em C, peneiramento de cascalho. Em $D$, minerais pesados concentrados indicados pela seta. 
Grupo Bauru e, secundariamente, a Formação Palermo (Vasconcelos, 2007). As rochas da Formação Marília são arenitos finos a imaturos e intensamente silicificados (silcretes), como observado no Garimpo do Cavoqueiro (Figuras 5A e B).

Os cascalhos normalmente possuem clastos que variam de grânulos a matacões e, eventualmente, ocorrem blocos. Entre os clastos predominam os de quartzo arenito, quartzo, silexito e laterita (Figuras 5C e D). Os dois primeiros tipos apresentam esfericidade média a alta e arredondamento bom a muito bom. Nos demais, a esfericidade é baixa e o arredondamento é ruim. A matriz é composta por argila a areia grossa e, por vezes, há cimento incipiente de óxidos de ferro. $\mathrm{O}$ arcabouço dos cascalhos varia de fechado (clasto suportado) a aberto (matriz suportando clastos) e a gradação é normal e, por vezes, inversa Walker (1975). As areias maturas a imaturas (Figura 5D) e por vezes, argilosas, cobrem os cascalhos.

Os pacotes de placeres possuem cores branca a marron amareladas quando situados junto ao canal ou na planície de inundação e cores vermelhas a amareladas quando dispostos em terraços. Os primeiros são denominados pelos garimpeiros de grupiaras e os outros de monchões.
A razão estéril/minério varia na proporção de 0:1 no canal e 3:1 nos terraços. A partir dos perfis $A A^{\prime}$ e $B B^{\prime}$ (Figuras 6 e 7) é possível sugerir o empilhamento estratigráfico dos pacotes areno-cascalhosos que, do mais antigo para o mais jovem, são aqui denominados informalmente de T2 a T0. Geralmente os placeres T2 são aqueles posicionados em cotas topográficas acima de 550 $\mathrm{m}$ e estão distribuídos ao longo de ambas as margens do Rio Itiquira, recobrindo parte da Formação Marília. Os pacotes tipo T1 ocorrem ao longo das cotas topográficas situadas entre 500 a $550 \mathrm{~m}$. Os cascalhos TO são aqueles posicionados geograficamente junto ao rio, afluentes e depositados em cotas topográficas abaixo de $500 \mathrm{~m}$. Os cascalhos dos terraços mais elevados apresentam seixos a matacões com tipos litológicos similares a aqueles encontrados no T1 e T0; porém, o tamanho dos clastos, em média, difere. Os cascalhos tipo T2 são mais finos, enquanto que os cascalhos tipo T0 são em média mais grossos. Isto decorre do retrabalhamento realizado pelos eventos deposicionais T0 sobre os pacotes mais antigos T1 e T2.
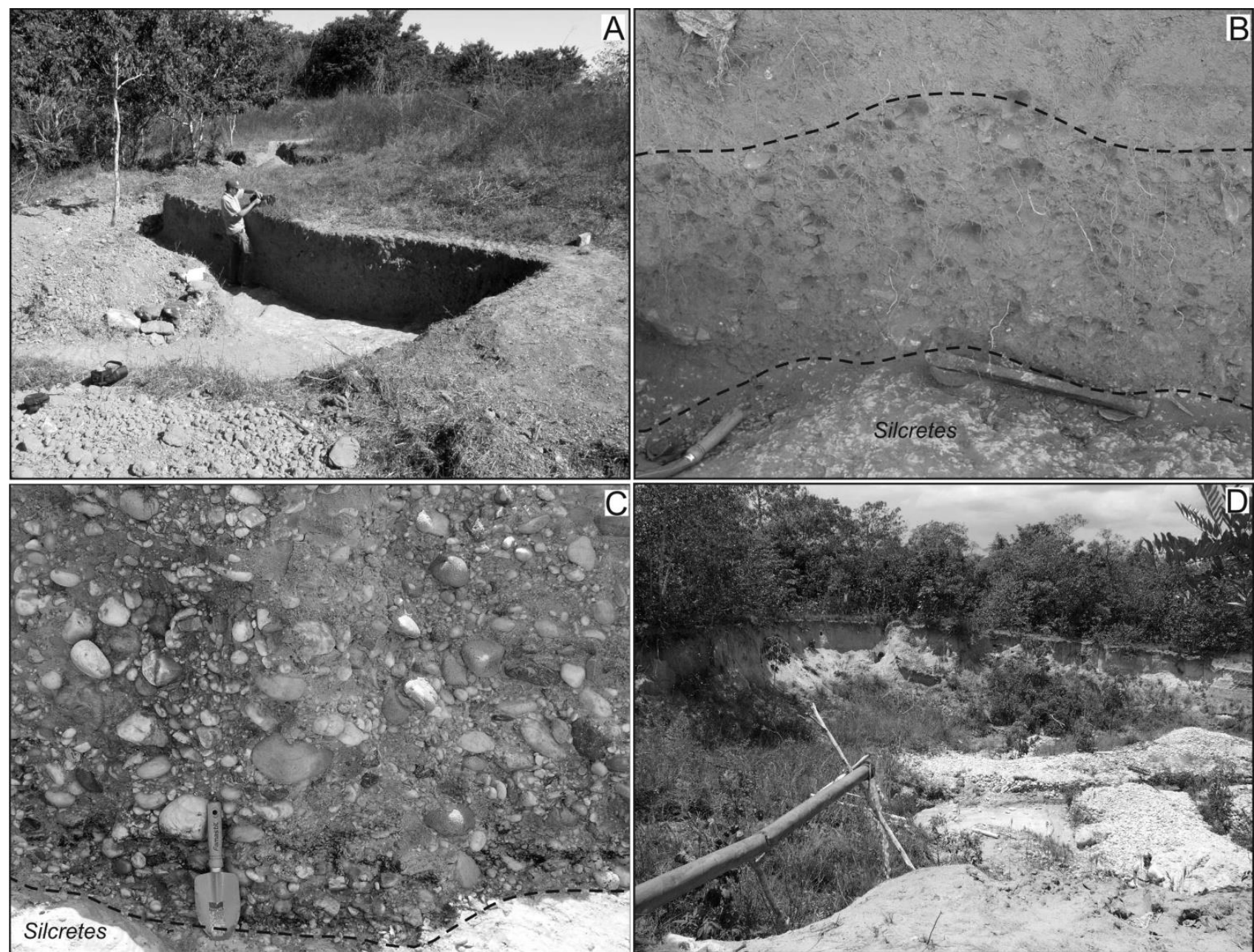

Figura 5 - Em A, escavação aberta no garimpo do Cavoqueiro. Em B, detalhe do contato discordante erosivo entre cascalho diamantífero no topo e os silcretes da Formação Marília na base. Em C, detalhe do cascalho clasto suportado no topo em contato discordante erosivo com silcretes. Em D, garimpo da Fazenda Velha, com destaque para a cobertura estéril branca. 
$(\mathrm{m})$

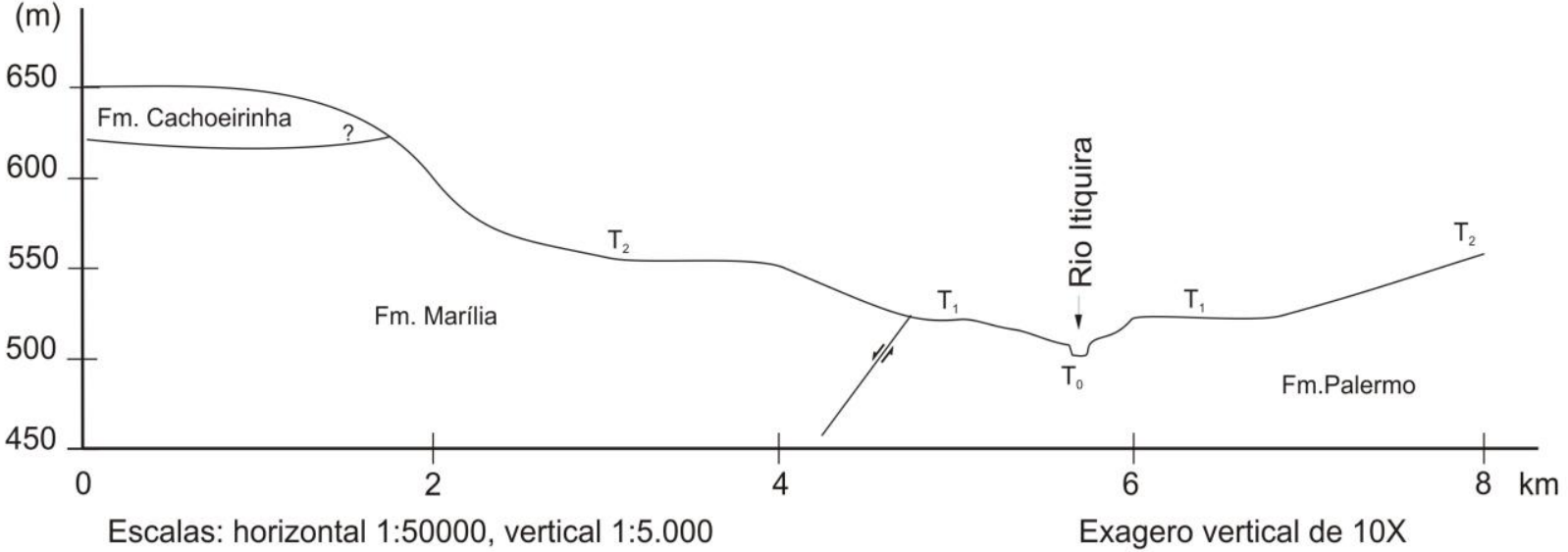

Figura 6 - Perfil Geológico AA". Mostra as formações Palermo e Marília sobrepostas por cascalhos dos "terraços" T2 e T1. O T0 é o canal atual do Rio Itiquira.

B

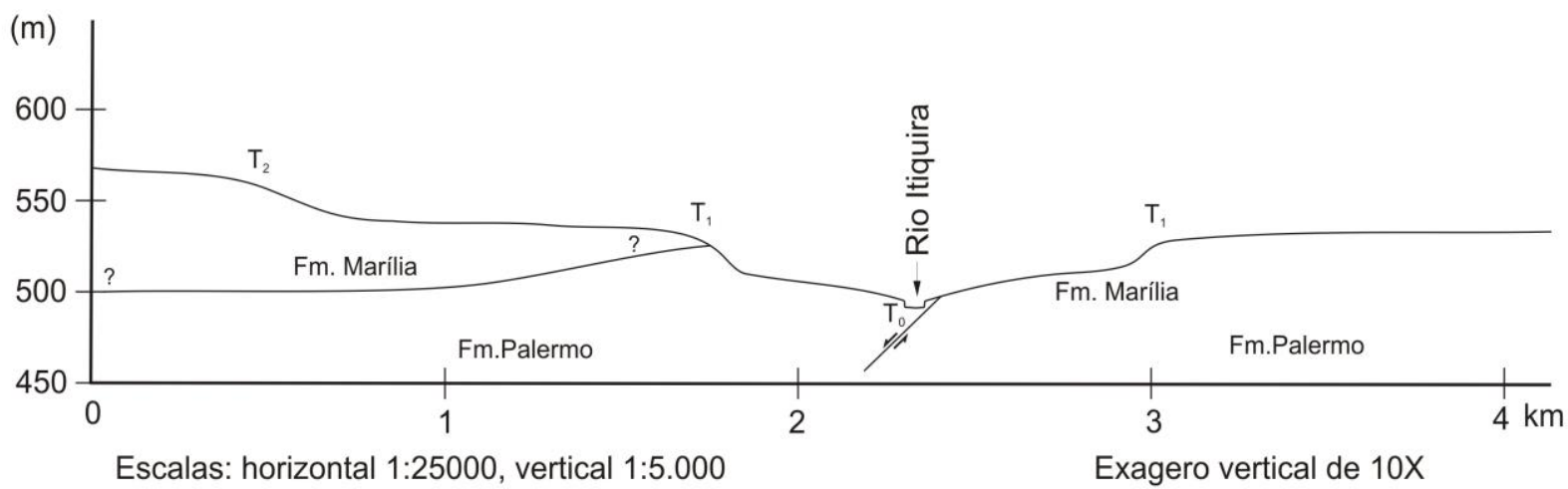

Figura 7 - Perfil Geológico BB'. Mostra a distribuição dos "terraços" T2 e T1 em relação ao Rio Itiquira (T0) e no bedrock as formações Palermo e Marília.

Armadilhas em ambiente fluvial constituem estruturas controladoras da evolução do rio e de captura (concentração) de recursos minerais, resultantes de condicionamentos hidrodinâmicos, litologia do bedrock, evoluções geomorfológica e tectônica. $\mathrm{Na}$ área estudada foram identificadas armadilhas tipo bolsões, panelas, veias e ajogo (Figuras 8 A a D), conforme descrito por Weska (1996a). As duas primeiras armadilhas são formas erosivas que predominam no bedrock dos garimpos do Cavoqueiro e Fazenda Velha, todavia foram vistas também no leito do rio, próximo ao garimpo do Bode. Veias são canais de corte e preenchimento (cut and fill), de pequeno porte e foram observadas nos cascalhos ou no limite entre o bedrock e o cascalho, como por exemplo, no garimpo do Cavoqueiro. 0 ajogo é um depósito de barra de pontal que ocorre no meandro do rio (Figura 8D) e a evolução desta armadilha foi controlada por falhas NE e NW.

\section{Idades por luminescência do quartzo}

No Brasil os primeiros registros sobre a aplicação deste método de datação absoluta ocorreram a partir do ano de 1950; entretanto, a aplicação mais intensa em sedimentos iniciou a partir de 1980 (Sallun et al. 2007). Em Mato Grosso não há registro desta utilização.

Os resultados das datações deste trabalho são apresentados na Tabela 1. Estes dados, associados ao empilhamento estratigráfico do quaternário local, mais os perfis geológicos, permitem diferenciar os eventos mais jovens dos antigos. A idade de $720 \pm 120$ anos da amostra EIT 14, corresponde aos depósitos atuais a subatuais T0; enquanto que, a idade de $8400 \pm 858$ anos, da amostra EIT 05, aos depósitos mais antigos e do terraço T1, Figura 9A. As idades obtidas nas amostras EIT 07, 11 e 13, respectivamente, Figuras $9 \mathrm{~B}$ e $9 \mathrm{~A}$, foram interpretadas como retrabalhamento dos terraços mais antigos por eventos erosivos mais jovens e por reativação neotectônica da bacia.

O conjunto de idades mostra que parte dos placeres diamantíferos do Rio Itiquira são holocênicos, principalmente aqueles eventos relacionados à T0 e T1. Em função do pequeno número de amostras e este trabalho não ter amostrado todos os terraços, pressupõe-se idades pleistocênicas para placeres nos terraços mais elevados > $550 \mathrm{~m}$ e assim melhor definir a evolução deste rio no Quaternário. 


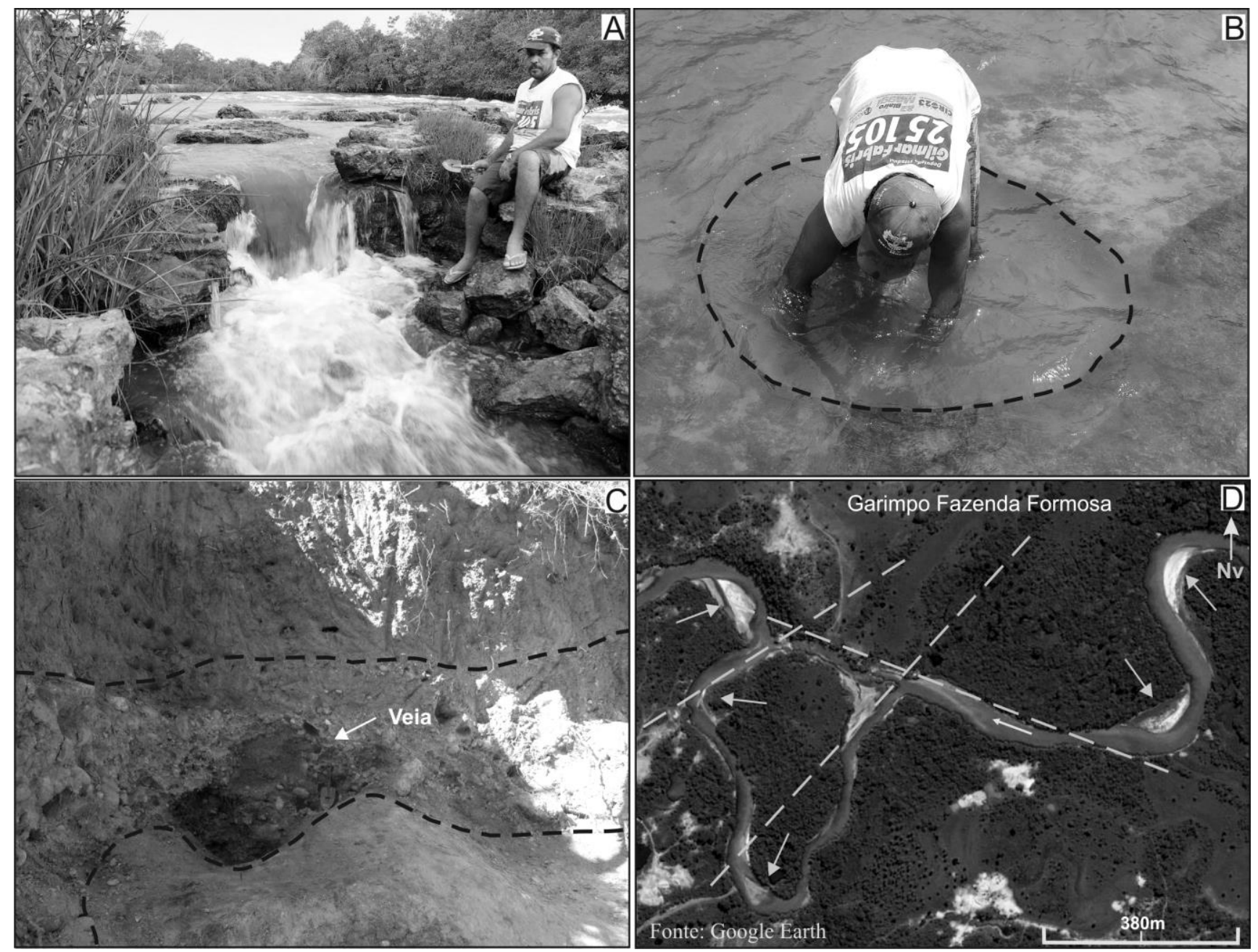

Figura 8 - Tipos de armadilhas (traps). Em A, bolsão próximo ao garimpo do Bode. Em B, panela no Cavoqueiro. Em C, veia (cut and fill) em pacote cascalhoso. Em D, barras de pontal (ajogo) na Fazenda Formosa mostradas pelas setas.

Tabela 1 - Idades dos pacotes quaternários obtidas pelo método de Luminescência Opticamente Estimulada (LOE).

\begin{tabular}{|c|c|c|c|}
\hline PONTOS & UNIDADE & LOCAL & IDADE/ANOS \\
\hline EIT 05 & $\mathrm{T}_{1}$ & GARIMPO DO CAVOQUEIRO & $1700 \pm 858$ \\
\hline EIT 07 & $\mathrm{T}_{0}$ & FAZENDA FORMOSA & $4100 \pm 430$ \\
\hline EIT 11 & $\mathrm{T}_{1}$ & FAZENDA FORMOSA & $660 \pm 90$ \\
\hline EIT 13 & $\mathrm{T}_{1}$ & GARIMPO DO CAVOQUEIRO & $720 \pm 120$ \\
\hline EIT 14 & $\mathrm{T}_{0}$ & GARIMPO DO CAMBAUVA & \\
\hline
\end{tabular}

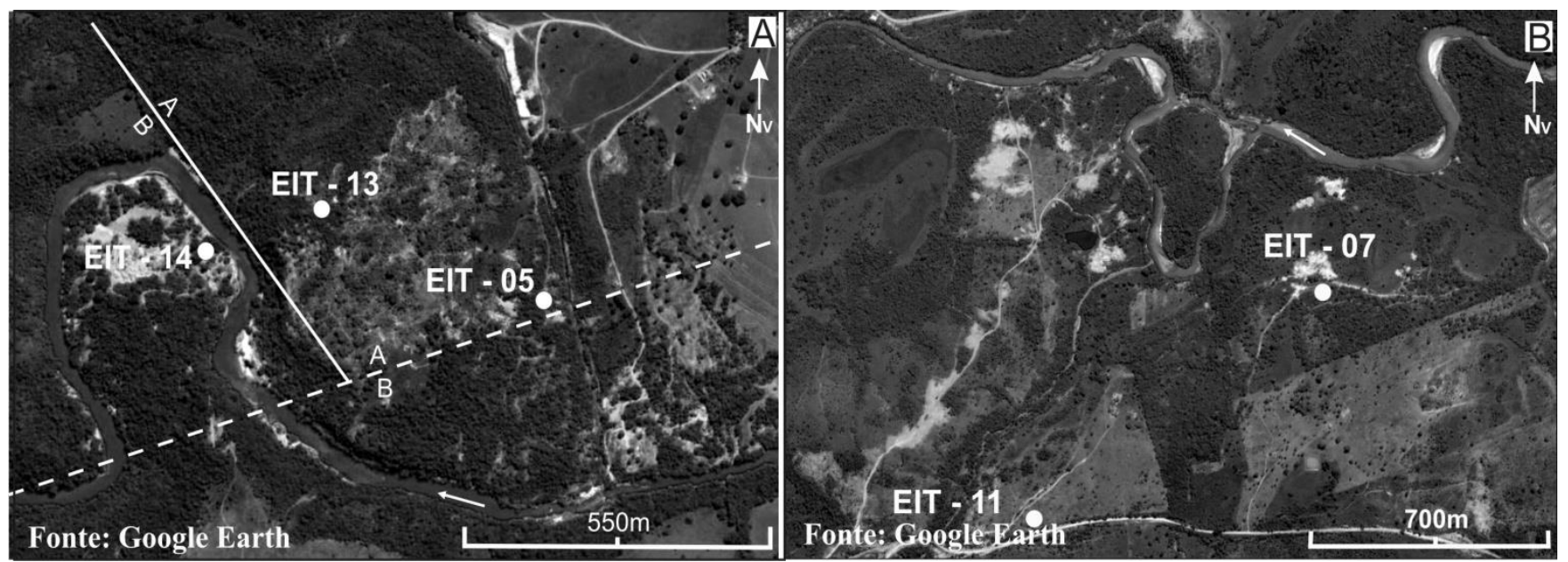

Figura 9 - Pontos amostrados para datação por LOE. 


\section{Minerais pesados}

O estudo de minerais pesados em depósitos secundários diamantíferos no mundo constitui um método de prospecção de vital importância para a prospecção de fontes primárias kimberlítica, lamproítica ou outras, conforme Addad (2001). O estudo da química de minerais indicadores norteia a prospecção de fontes primárias e contribui para o entendimento da provável gênese destes minerais. Por exemplo, minerais indicadores para kimberlito são as granadas G3D, G4D, G5D e G10D (Grütter et al. 2004), a picroilmenita, o espinélio e o cromodiopsído, principalmente. No caso de lamproíto, os minerais indicadores são: cromita, andradita, zircão, manganoforita, Ba-flogopita, priderita e wadeita (Gold 1984).

Em Mato Grosso existem trabalhos que trataram sobre a prospecção, a gênese e/ou fertilidade dos corpos primários por meio da química mineral de minerais indicadores, como por exemplo, Weska (1996), Greenwood et al. (1998) e Greenwood (2001). Estudos sobre minerais indicadores e acompanhantes em depósitos de paleoplaceres e placeres estão descritos em Weska et al. (1984), Weska $(1987,1996)$ e Bittencourt Rosa et al. (1993).

Os grãos de minerais pesados identificados em lupa binocular, com denominações utilizadas por garimpeiros em parêntesis, foram: o diamante na Figura 10; a magnetita; safira (azulinha); granada (chicória); ilmenita (pretinha); rutilo; zircão (microdiamante); e, óxidos de ferro (feijão).

O percentual em peso de óxidos das granadas nas amostras EIT 14_1 a 14_7 (Tabela 2) situa-se entre 0,16 a 9,68 para o $\mathrm{MgO}$; são empobrecidas em $\mathrm{Cr} 2 \mathrm{O} 3$ com 0 a 0,06 ; os valores de $\mathrm{CaO}$ são baixos a altos, respectivamente, 0,31 a 7,19; o conteúdo de MnO entre 0,54 a 26,05; o FeOt de 16,24 a 27,70; o TiO2 varia entre 0,02 e 0,15; e, o Na2O entre 0 a 0,15 . Resulta que duas composições moleculares de granadas existem. A primeira dominada pelo $\mathrm{Fe} 2+$, associada a Mg, caracterizada pelo par Alm42-55; Py31-40 e seguido de Gr3-16, And2-6 e Sp1-2. A segunda destaca o $\mathrm{Mn}$ em paragênese com o $\mathrm{Fe} 2+$, o par molecular dominante é Sp44-52; Alm42-47, seguido de Py1-8 e And1-2.

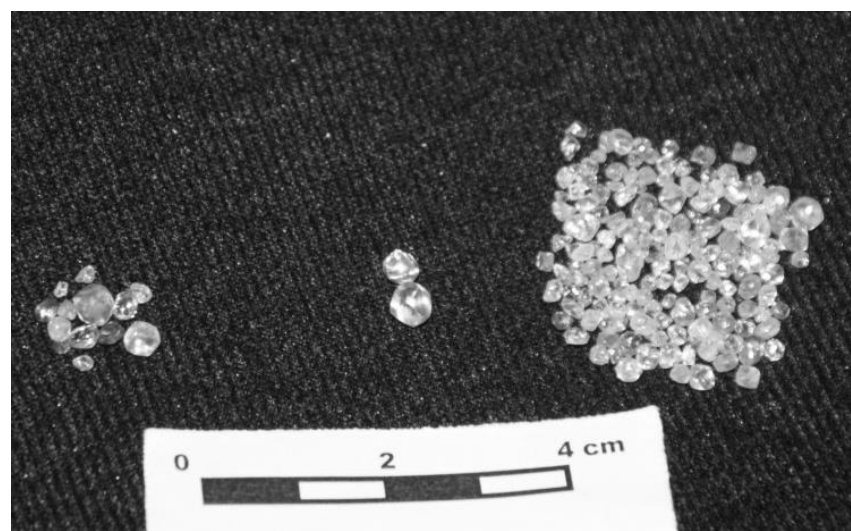

Figura 10 - Diamantes capturados em garimpos de Itiquira.

Um diagrama $\mathrm{CaO} \times \mathrm{Cr} 2 \mathrm{O} 3$ foi construído para as granadas analisadas e o resultado é mostrado na Figura 11.
Este diagrama foi proposto por Dawson \& Stephens (1975) para discriminar granadas peridotíticas (G10), Iherzolíticas (G9) e eclogíticas (G3). Grütter et al. (2004) adicionaram a este diagrama intervalos de percentuais de outros óxidos, como é o caso do TiO2, MgO, Na2O, FeO e o MGNUM= $(\mathrm{MgO} / 40,3) /(\mathrm{MgO} / 40,3+\mathrm{FeOt} / 71,85)$ [óxidos \%], que permitem a classificação detalhada e individualizar granadas G0, G1, G3, G4, G5, G9, G10, G11 e G12. Granadas G9, G5, G4, G3 e G1 possuem campos em sobreposição que são discriminados por estes óxidos e o MGNUM. As granadas G3, G4, G5 e G10, com Na2O > 0,07\%, de acordo com Grütter et al. (2004), sugerem associação composicional e de P-T com o diamante e as quais se adiciona o sufixo "D".

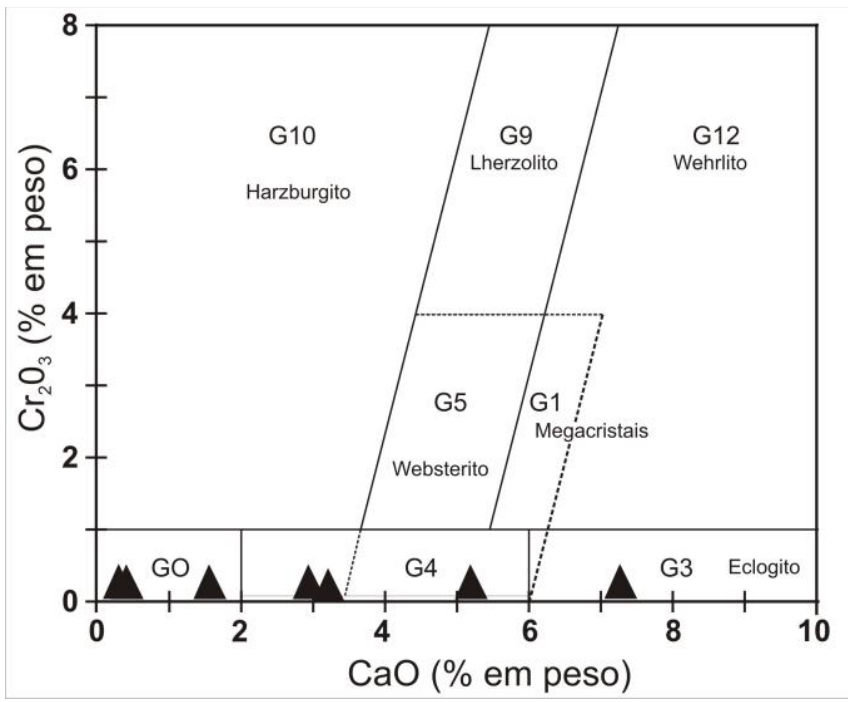

Figura 11 - Diagrama Cr203 vs $\mathrm{CaO}$ com os campos segundo Grütter et al. (2004). As granadas do Rio Itiquira são de variedades G0 (crustal), G3 (eclogito) e G4 (piroxenito).

As granadas das amostras EIT14_1 a 7, tratadas pelo método proposto por Grütter et al. (2004), plotam nos campos G0, G3 e G4. O conteúdo de $\mathrm{Na2O}$ na granada da amostra EIT 14_3 é de 0,09 (Tabela 2) e é G4D. Sendo assim, entre as granadas coletadas no Rio Itiquira foram identificadas G0, G3, G4 e G4D. As granadas G0 (EIT 14_4, $14 \_6$ e 14_7) com valores elevados de $\mathrm{Mn}$ (18,38 a 26,05\%) e valores baixos de $\mathrm{CaO}(0,31$ a 1,56\%) e $\mathrm{Cr} 2 \mathrm{O} 3$ ( 0 a 0,02\%), não ocorrem em kimberlitos. As granadas G4 e G3 sugerem, respectivamente, fontes piroxenítica e eclogítica, enquanto a granada G4D indica associação com fonte kimberlítica fértil em diamante (Grütter et al. 2004).

As ilmenitas das amostras EIT14_8 a 10 possuem baixos valores de $\mathrm{MgO}$ (0 a 1,44\%) e elevados de $\mathrm{MnO}(1,36$ a $7,29 \%)$. Os percentuais em peso de $\mathrm{TiO} 2$ variam de 49,41 a 53,41; e, o de FeOt entre 41,69 a 43,51, Tabela 2. A composição molecular é IIm94-99, Geik0-6, Hem0-6 e plotam nos campos de granito e basalto do diagrama da Figura 12 proposto por Mitchel (1986). Kaminsky \& Belousova (2009) descreveram valores elevados de $\mathrm{MnO}$ $(0,63$ a 2,49\%) e baixos de $\mathrm{MgO}(0$ a $0,24 \%)$ em ilmenitas 
Tabela 2 - Dados de química mineral de minerais pesados em percentual em peso.

\begin{tabular}{|c|c|c|c|c|c|c|c|c|c|c|c|c|c|}
\hline Amostra & $\mathbf{N a}_{\mathbf{2}} \mathbf{O}$ & $\mathbf{M g O}$ & $\mathbf{A l}_{\mathbf{2}} \mathbf{O}_{\mathbf{3}}$ & $\mathbf{S i O}_{\mathbf{2}}$ & $\mathbf{K}_{\mathbf{2}} \mathbf{O}$ & $\mathbf{C a O}$ & $\mathbf{T i O}_{\mathbf{2}}$ & $\mathbf{C r}_{\mathbf{2}} \mathbf{O}_{\mathbf{3}}$ & $\mathbf{M n O}$ & $\mathbf{F e O t}$ & $\mathbf{N i O}$ & Total & $\mathbf{M i n e r a l}$ \\
\hline EIT14_1 & 0,06 & 8,68 & 22,06 & 38,81 & 0,00 & 3,22 & 0,07 & 0,00 & 0,55 & 25,20 & 0,03 & 98,69 & granada \\
\hline EIT14_2 & 0,07 & 6,89 & 21,08 & 36,51 & 0,01 & 5,18 & 0,02 & 0,06 & 1,48 & 27,24 & 0,02 & 98,57 & granada \\
\hline EIT14_3 & 0,09 & 9,68 & 22,15 & 36,29 & 0,05 & 3,19 & 0,05 & 0,04 & 0,54 & 27,70 & 0,08 & 99,87 & granada \\
\hline EIT14_4 & 0,15 & 0,19 & 19,95 & 35,88 & 0,06 & 1,56 & 0,15 & 0,02 & 26,05 & 16,24 & 0,00 & 100,23 & granada \\
\hline EIT14_5 & 0,05 & 8,75 & 21,83 & 36,69 & 0,04 & 7,19 & 0,10 & 0,00 & 0,46 & 23,80 & 0,00 & 98,91 & granada \\
\hline EIT14_6 & 0,00 & 0,16 & 20,52 & 33,72 & 0,02 & 0,67 & 0,08 & 0,00 & 20,60 & 23,04 & 0,02 & 98,83 & granada \\
\hline EIT14_7 & 0,05 & 1,93 & 20,48 & 35,38 & 0,02 & 0,31 & 0,14 & 0,00 & 18,38 & 23,64 & 0,02 & 100,35 & granada \\
\hline EIT14_8 & 0,03 & 1,44 & 0,05 & 0,21 & 0,02 & 0,03 & 53,41 & 0,07 & 1,36 & 43,12 & 0,01 & 99,76 & ilmenita \\
\hline EIT14_9 & 0,00 & 0,07 & 0,00 & 0,11 & 0,04 & 0,00 & 50,91 & 0,00 & 2,96 & 43,51 & 0,00 & 97,61 & ilmenita \\
\hline EIT14_10 & 0,02 & 0,00 & 0,04 & 0,21 & 0,02 & 0,01 & 49,41 & 0,00 & 7,29 & 41,69 & 0,00 & 98,69 & ilmenita \\
\hline EIT14_11 & 0,05 & 0,00 & 0,06 & 0,09 & 0,00 & 0,01 & 98,98 & 0,20 & 0,00 & 0,57 & 0,06 & 100,02 & rutilo \\
\hline EIT14_12 & 0,00 & 0,02 & 0,07 & 0,14 & 0,01 & 0,00 & 96,95 & 0,40 & 0,00 & 0,21 & 0,06 & 97,86 & rutilo \\
\hline EIT14_13 & 0,05 & 0,00 & 0,09 & 0,15 & 0,01 & 0,00 & 97,11 & 0,25 & 0,00 & 0,83 & 0,00 & 98,47 & rutilo \\
\hline
\end{tabular}

manganesíferas de kimberlitos em Juína, que também ocorrem em Guaniamo, Venezuela e sugeriram tratar-se de um indicador distinto para kimberlito. Os percentuais em peso de $\mathrm{MgO}$ e $\mathrm{MnO}$ nas ilmenitas analisadas são elevados, quando comparados aos das ilmenitas de kimberlitos em Juína. São também muito mais elevados do que em picroilmenita de kimberlito $(0,2$ a $0,3 \%)$ e sugerem fonte distinta de kimberlito.

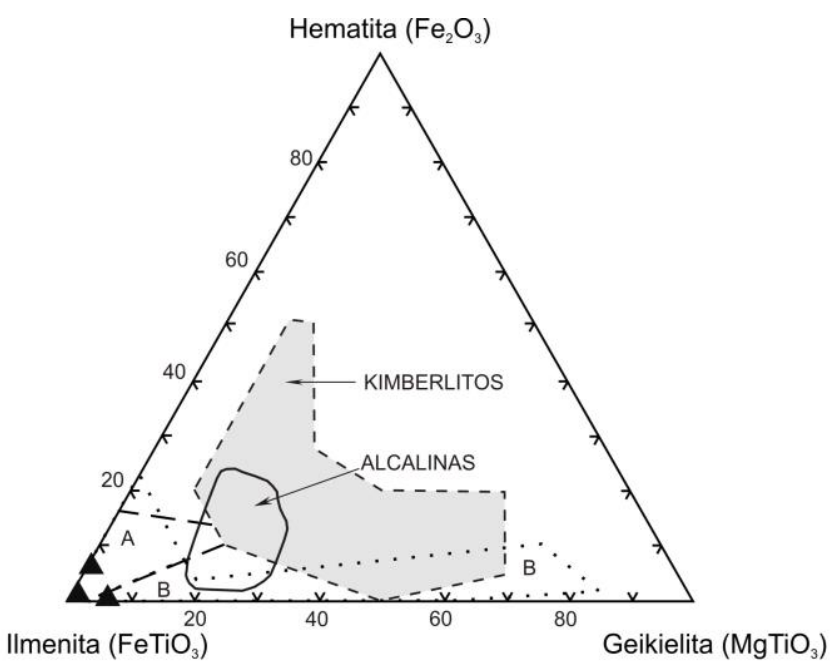

Figura 12 - Diagrama Fe2O3-FeTiO3-MgTiO3, mostrando os campos de ilmenitas de kimberlitos, de rochas alcalinas, de granitos (A) e basaltos (B) extraídos de Mitchel (1986). As ilmenitas do Rio Itiquira plotam em A e B.

\section{Conclusões}

Os garimpos em Itiquira representaram em passado recente importante atividade econômica local e contrastam com o declínio atual. As frentes de garimpos abandonadas estudadas permitiram o empilhamento estratigráfico de depósitos diamantíferos quaternários.

Os depósitos cascalhosos foram subdivididos informalmente em T0 a T2 e são hospedeiros de diamante. As armadilhas do diamante identificadas nestes placeres foram panela, bolsão, veia (canal de corte e preenchimento) e ajogo (barra de pontal).

A idade mais jovem de $720 \pm 120$ anos foi obtida na amostra EIT 14 (Cambaúva), em cascalhos do canal atual do rio e TO. A mais antiga, no terraço da margem direita do rio, amostra EIT 05 (Cavoqueiro), T1, com idade de $8400 \pm 858$ anos e situam estes depósitos no Holoceno. As demais idades não refletem a idade de sedimentação, mas retrabalhamento dos terraços mais antigos por eventos erosivos mais jovens (TO).

O estudo de minerais pesados indicadores e acompanhantes proporcionou a identificação de magnetita, safira, granada, ilmenita, rutilo e zircão. A partir da química mineral de minerais indicadores foram identificadas granadas $\mathrm{G0}$ e $\mathrm{G} 4+\mathrm{G} 3$. A primeira não tem relação com fontes primárias kimberlíticas. A segunda é indicadora de fonte piroxenítica a eclogítica (Grütter et al. 2004), com baixo $\mathrm{Cr} 2 \mathrm{O} 3$ e médio a alto $\mathrm{CaO}$. Entre as granadas $\mathrm{G} 4$, o percentual em peso de $\mathrm{Na} 2 \mathrm{O}$ na granada da amostra EIT14_3 é 0,09. Neste caso é uma granada G4D e indicadora de fontes primárias férteis em diamante. As ilmenitas estudadas são distintas de ilmenita magnesiana (picroilmenita) encontrada em kimberlito devido ao baixo conteúdo de $\mathrm{MgO}$ e o elevado de $\mathrm{MnO}$. A plotagem das ilmenitas no diagrama $\mathrm{Fe} 2 \mathrm{O3}-\mathrm{FeTiO3}-\mathrm{MgTiO} 3$ mostra derivação de fontes granítica e de basalto.

Agradecimentos: Os autores agradecem a FATEC Laboratório de vidro e datação pela obtenção das idades dos sedimentos, em especial a professora Sonia H. Tatumi e toda sua equipe. Agradecemos também o laboratório de Microssonda Eletrônica da UFRGS, em particular a professora Márcia Elisa Boscato e a técnica Juscelania Tramontina pela realização das análises de química mineral. Ao laboratório de laminação da UNB pelo suporte na montagem das seções de grãos e aos trabalhadores de Itiquira: Jucelino, Manoel, Paulo, Detinho e Dito, que se empenharam em nos fornecer dados sobre os garimpos e pelo acompanhamento nas etapas de campo. 


\section{Referências bibliográficas}

ADDAD J.E. 2001. Minerais pesados uma ferramenta para prospecção, proveniência, paleogeografia e análise ambiental. Imprensa Universitária, Centro Gráfico da UFMG, 69p.

ALMEIDA F.F.M. 1959. Traços gerais de geomorfologia do centrooeste brasileiro. In: Lacerda Filho et al. 2004. Geologia e recursos minerais do Estado de Mato Grosso, Programa Integração, Atualização e Difusão de Dados da Geologia do Brasil. Sistema de Informação Geográfica-GIS, Ministério de Minas e Energia, Secretaria de Minas e Metalurgia. Escala 1:000.000, 252p.

BITTENCOURT ROSA. D., WESKA R.K., MENEZES LIMA P.R. 1993. Certas formas de sílicas fibrosas associadas à mineralizações diamantíferas na região de Água Fria, Município de Chapada dos Guimarães, MT, Brasil, In: 1o Simpósio Brasileiro de Geologia do Diamante, Cuiabá, MT, Anais. Cuiabá, Ed. UFMT, Gráfica Universitária, 152-163.

DAWSON J.B., STEPHENS W.E., 1975. Statistical classification of garnets from kimberlite and associated xenoliths. Journal Geology. 83: 589-607.

GIBSON S.A., THOMPSON R.N., WESKA R.K., DICKIN A.P., LEONARDOS O.H. 1997. Late Cretaceous rift-related upwelling and melting of the Trindade starting mantle plume head beneath western Brazil, Contributions to Mineralogy and Petrology, Contributions to Mineralogy and Petrology, 126: 303-314.

GOLD, D.P. 1984. Properties and tectonic setting for diamond bearing rocks, New York, Engineering \& Mining Journal, 9-10.

GREENWOOD J.C., GIBSON S.A., THOMPSON R.N., WESKA R.K., DICKIN A.P. 1998. Petrogensis of cretaceous kimberlites from the Paranatinga region, Central Brazil, In: 7th International Kinberlite Conference, Extended Abstracts, Cape Town, South Africa, p. 268-270.

GREENWOOD J.C. 2001. The secular geochemical evolution of the Trindade mantle plume. Thesis (Ph.D.). Cambridge University, UK, 298p.

GRÜTTER H.S., GURNEY J.J., MENZIE A.H., WINTER F. 2004. An updated classification scheme for mantle-derived garnet, for use by diamond explorers. Lithos, 77: 841-857.

KAMINSKY F.V., BELOUSOVA E.A. 2009. Manganoan ilmenite as kimberlite/diamond indicator mineral. Russian Geology and Geophysics, 50:1212-1220.

MARQUES M.D. 2004. História do Município de Itiquira. Lei de Incentivo a Cultura, Gráfica União, 100p.

MITCHEL, R.H. 1986. Kimberlites: mineralogy, geochemistry, and petrology. Plenum Press, New York, 442p.

OLIVEIRA A.I., LEONARDOS O.H. 1943. Geologia do Brasil 2a ed. Rio de Janeiro, Serviço de Informação Agrícola, 813p. (Série Didática 2).

SALLUN A.E.M., SUGUIO K., TATUMI S.H., YEE M., SANTOS J., BARRETO A.M.F. 2007. Datação absoluta de depósitos quaternários brasileiros por luminescência, Brasil. Revista Brasileira de Geociências, 37(2): 402-413.

TATUMI S.H., SILVA L.P., PIRES E.L., ROSSETTI D.F., GÓES A.M., CASIMIRO S. MUNITA C.S. 2008. Datação de sedimentos pósBarreiras no norte do Brasil: Implicações Paleogeográficas. Revista Brasileira de Geociências, 38(3): 514-524.

VASCONCELOS L.A. 2007. Processos erosivos na sub-bacia hidrográfica do alto Rio Itiquira: bases técnicas para controle preventivo. Mestrado em Geografia. Programa de Pósgraduação em Geografia, Universidade Federal de Mato Grosso, 144p.
WALKER, R.G. 1975. Conglomerate: sedimentary structures and facies models. In: HARN, J.C.; SOUTHARD, J. B.; SPEARING, D.R., WALKER, R.G. (ed.), Depositional Enviroments as Interpreted From primary Sedimentary Structures and Stratifications Sequences, Texas, Econ. Paleont., Short Course 2, 133-161.

WESKA R.K., PERIN L.A., FERREIRA I.A. 1984. "Placers" diamantíferos da bacia do Alto Paraguai-MT, caracterização geológica como critérios e guias de prospecção. In: 33응 Congresso Brasileiro de Geologia, Rio de Janeiro, Anais. Rio de Janeiro, Sociedade Brasileira de Geologia, 8: 3.877-3887.

WESKA R.K. 1987. "Placers" diamantíferos da região de Água Fria, Chapada dos Guimarães, MT. Dissertação de Mestrado. Departamento de Geociências, Universidade de Brasília, 170p.

WESKA R.K., SVISERO D.P., LEONARDOS O.H. 1996. Contribuição ao conhecimento do Grupo Bauru no Estado de Mato Grosso, Brasil. In: $4^{\circ}$ Simpósio sobre o Cretáceo do Brasil, Instituto de Geociências e Ciências Exatas, Universidade Estadual Paulista, Águas de São Pedro e Rio Claro, 289-295.

WESKA R.K. 1996. Geologia da região diamantífera de Poxoréu e áreas adjacentes, Mato Grosso. Tese de Doutorado. Instituto de Geociências, Departamento de Mineralogia e Petrologia, Universidade de São Paulo, 219p.

WESKA R.K. 1996a. A prospecção aluvionar de diamantes a partir do entendimento de armadilhas "traps". In: $39^{\circ}$ Congresso Brasileiro de Geologia, Salvador, Anais. Salvador, Sociedade Brasileira de Geologia, 3: 189-191.
Manuscrito ID 27123

Submetido em maio de 2012 Aceito em agosto de 2012 